\title{
La "Lex Artis ad hoc" como criterio valorativo para calibrar la diligencia exigible en todo acto o tratamiento médico. A propósito de un caso basado en la elección de la técnica empleada en el parto (parto vaginal vs. cesárea)
}

"La vida es corta, la técnica larga de aprender, el momento propicio fugitivo, la experiencia personal engañadora y la decisión difícil".

Hipócrates (460-377 a.n.e)
JE. Vázquez

Abogado. Sevilla.

Correspondencia: J. Enrique Vázquez López. E-mail: jevazquez@orange.es

Abogado. Sevilla.
Las personas que por primera vez y sin tener formación jurídica previa se acercan de primera mano a este mundo complejo y en cierta medida farragoso, como es el judicial forense, se asombran de inmediato por la clara abundancia existente en los textos escritos -normalmente sentencias y artículos doctrinales- de vocablos y expresiones de origen latino. Estas expresiones latinas se refieren a muy variados aspectos del Derecho, y hemos de decir que en la mayoría de los casos se elaboran con rancio abolengo aunque de moderno cuño, esto es, que aunque de hecho sean vocablos y expresiones construidas en latín, lengua madre de la nuestra, en realidad los juristas romanos no tienen ni podían tener ni idea de lo que hemos hecho con ellas, ya que las hemos aplicado y elaborado para situaciones actuales que no tenían por qué existir en la antigüedad.

La expresión que sirve de título a este espacio es un caso claro de lo que hemos dicho. En realidad, en la antigua Roma había médicos, de eso no hay duda: lo que no nos consta es si sus pacientes los demandaban cuando las cosas salían mal y se producía una "mala praxis", o una vulneración de la "lex artis ad hoc", expresiones que indudablemente se usaban para otras situaciones que no tenían nada que ver con lo que tratamos hoy.

El concepto de "Lex artis ad hoc" es una construcción jurisprudencial que se ha ido perfilando en varias sentencias a lo largo de los años, siendo quizás la más significativa de todas ellas la del Tribunal
Supremo de fecha 11 de marzo de 1991, que la define como "... aquel criterio valorativo de la corrección del concreto acto médico ejecutado por el profesional de la medicina - ciencia o arte médico que tiene en cuenta las especiales características de su autor, de la profesión, de la complejidad y trascendencia vital del paciente y, en su caso, de la influencia en otros factores endógenos -estado e intervención del enfermo, de sus familiares, o de la misma organización sanitaria-, para calificar dicho acto de conforme o no con la técnica normal requerida (derivando de ello tanto el acervo de exigencias o requisitos de legitimación o actuación lícita, de la correspondiente eficacia de los servicios prestados, y, en particular, de la posible responsabilidad de su autor/médico por el resultado de su intervención o acto médico ejecutado)...".

En otros tratados suele definirse la "lex artis" o la "lex artis ad hoc" como el conjunto de prácticas médicas aceptadas como adecuadas para tratar al enfermo en el momento de que se trata.

En la práctica, la "lex artis" -literalmente ley del arte, en este caso del arte médico- funciona como un concepto jurídico indeterminado, ya que, como estamos viendo, se exige una actitud concreta del profesional sanitario cuya corrección o no dependerá de haber actuado conforme a los protocolos y normas de actuación de cada especialidad, normas que son cambiantes conforme la Medicina y los descubrimientos científicos van avanzando. 
Como tal concepto indeterminado, su concreción depende del caso concreto y de las concretas circunstancias de tiempo y lugar. No es lo mismo una operación de apéndice en plena selva amazónica que en un hospital con todos los medios disponibles. Igualmente, la conducta exigible a un médico hace veinte años no es la misma que ha de ser aplicable a día de hoy, y ello por razones obvias: los conocimientos han cambiado y lo que antes podía ser válido en Medicina, hoy ya no lo es.

\section{La sentencia concreta}

Para ilustrar lo que estamos diciendo nos valemos de una Sentencia del Tribunal Supremo de fecha 29 de enero de 2010, de la Sala Primera de lo Civil. Su Ponente, el Excmo. D. José Antonio Seijas Quintana.

\section{La primera instancia}

D. Luis Pablo y Doña Silvia formularon demanda de juicio ordinario en representación de su hijo menor de edad Constancio, contra Don Ambrosio, Doña Constanza, la Entidad Clínica Santa Elena y la entidad Mapfre Caja Salud de Seguros y Reaseguros S.A., en reclamación de cantidad por los daños y perjuicios sufridos a resultas de la asistencia sanitaria recibida por Doña Silvia desde el inicio de su embarazo hasta el parto, imputando a los demandados las consecuencias lesivas sobre el plexo branquial padecidas por el nacimiento de su hijo Constancio, así como el perjuicio que resulta de un diagnóstico tardío de la cardiopatía que sufría con carácter congénito y que determinó la correspondiente intervención quirúrgica en una situación de urgencia y extrema gravedad.

De la demanda anterior, conoce el Juzgado de Primera Instancia $n^{\circ} 48$ de Madrid. Tras la tramitación pertinente, con fecha 25 de febrero de 2005, recae Sentencia desestimando íntegramente la demanda, al considerar que no se había acreditado negligencia alguna por parte de los profesionales que intervinieron en el seguimiento y en el parto de la demandante.

\section{La segunda instancia}

Recurrida la Sentencia anterior en apelación, con fecha $\mathbf{1 5}$ de julio de $\mathbf{2 0 0 5}$ se resuelve el recurso, y la Sección 19 de la Audiencia Provincial de Madrid estima en parte el recurso, con el siguiente fallo:

"Que estimando en parte el recurso de apelación formulado por D. Luis Pablo y Doña Silvia contra la sentencia de fecha 25 de febrero de 2005 dictada por el Juzgado de Primera Instancia $n^{\circ} 48$ de Madrid en el procedimiento a que se contrae el presente rollo, debemos revocar dicha resolución y estimando parcialmente la demanda en su día formulada por los citados apelantes contra D. Ambrosio, Doña Constanza, Clínica Santa Elena y Mapfre Caja Salud de Seguros y Reaseguros S. A. condenamos a los demandados al pago a los actores de forma conjunta y solidaria de la suma total de 300.000 Euros, en función de las proporciones que se han puesto de manifiesto en el fundamento jurídico Octavo de la presente resolución, y al pago de los intereses legales conforme se establece en el fundamento jurídico noveno de la misma. Todo ello sin expresa imposición de las costas procesales causadas en el litigio."

\section{Los recursos de casación y la sentencia del Tribunal Supremo}

Ante esta nueva Sentencia, recurren los demandados alegando varios motivos de casación, siendo los fundamentales -para no detenernos en exceso- los relativos a la vulneración del artículo 1.902 del Código Civil, que, nunca está de más recordarlo, es del siguiente tenor literal:

Art. 1.902 C.C.: El que por acción u omisión causa daño a otro, interviniendo culpa o negligencia, está obligado a reparar el daño causado.

Hacen hincapié por ello los recurrentes en que no se ha demostrado en modo alguno la negligencia exigible para que nazca la obligación de indemnizar, por lo que, en realidad, existe infracción del precepto citado habida cuenta que la sentencia recurrida convierte en objetiva la responsabilidad de los médicos demandados, considerando la del médico una obligación de resultados y no de medios.

El Tribunal Supremo, tras analizar la cuestión, estima los motivos planteados realizando el siguiente razonamiento, que por su importancia, recogemos de manera literal y entrecomillada, siendo nuestras las negrillas:

"El médico, en su ejercicio profesional, es libre para escoger la solución más beneficiosa para el bienestar del paciente poniendo a su alcance los recursos que le parezcan más eficaces en todo acto o tratamiento que decide llevar a cabo, siempre y cuando sean generalmente aceptados por la Ciencia médica, o susceptibles de discusión científica, de acuerdo con los riesgos inherentes al acto médico que practica, en cuanto está comprometido por una obligación de medios en la consecución de un diagnóstico o en una terapéutica determinada, que tiene 
como destinatario la vida, la integridad humana y la preservación de la salud del paciente (SSTS 24 de noviembre 2005; 8 de enero de 2006). Esta alternativa se plantea en los casos de partos que culminan el embarazo: el vaginal y la cesárea, y en ambos la diligencia del buen médico comporta no sólo la elección adecuada, sino el cumplimiento formal y protocolar de las técnicas previstas para cada uno conforme a una buena praxis médica y con el cuidado y precisión exigible de acuerdo con las circunstancias y los riesgos inherentes a la intervención según su naturaleza y circunstancias (STS 19 de octubre de 2007; 20 de julio 2009). Y si tan adecuado era uno y otro método para alumbrar al niño, lo que no es posible, sin alterar la doctrina expuesta, es establecer una relación de causalidad culposa entre la lesión resultante sobre el plexo braquial y el tipo de parto elegido, a partir de la opción por vía vaginal en lugar de la aplicación de la cesárea. Sin duda, existen numerosos factores de riesgo de distocia de hombros que los ginecólogos deben conocer e identificar para evitar los problemas que pudieran derivarse para aquellas mujeres de riesgo, pues ello forma parte de su actividad. Ahora bien, al margen del valor de predicción de estos factores de riesgo, lo cierto es que no había en el caso una indicación expresa que aconsejara una extracción por cesárea para prevenir el daño, antes al contrario, dice la sentencia que "las pruebas practicadas en los autos destacan la corrección en el tratamiento y preparación del parto, pero tampoco niegan que la indicación de la cesárea fuera incorrecto", es decir, admite que las pruebas reconocen la corrección de ambos medios y no obstante fundamenta su declaración de responsabilidad no en la comisión de una infracción, sino en la no negación por parte de los peritos de la indicación de la otra técnica para llevar a cabo el parto, como era la cesárea, y lo hace una vez conocido el resultado contrario a la salud del recién nacido pues tal concreción de los hechos supone que no había ningún dato que permitiera esperar un resultado distinto o que una vez seleccionado el método no se actuara con arreglo a la norma de conducta que exige un buen comportamiento profesional -lex artis-, pues es también hecho probado de la sentencia que "la técnica empleada en el parto para la resolución del problema surgido fue correcta y la actuación de la ginecóloga adecuada a la lex artis aplicable".

La valoración del nexo de causalidad exige ponderar que el resultado dañoso sea una consecuencia natural, adecuada y suficiente, valorada conforme a las circunstancias que el buen sentido impone en cada caso, y es evidente que para responsabilizar una determinada actuación médica no sirven simples hipótesis o especulaciones sobre lo que se debió hacer y no se hizo, cuando la extracción por vagina estaba médicamente justificada y no era posible exigirle otra distinta una vez conocido el resultado. La lex artis supone que la toma de decisiones clínicas está generalmente basada en el diagnóstico que se establece a través de una serie de pruebas encaminadas a demostrar o rechazar una forma de actuación. Implica por tanto la obligación del médico de realizar aquellas pruebas necesarias atendiendo el estado de la ciencia médica en ese momento, incluidos los protocolos indicativos para seguimiento de un embarazo y de un parto normalizado, de tal forma que, realizadas las comprobaciones que el caso requiera, sólo el diagnóstico que presente un error de notoria gravedad o unas conclusiones absolutamente erróneas, puede servir de base para declarar su responsabilidad, al igual que en el supuesto de que no se hubieran practicado todas las comprobaciones o exámenes exigidos o exigibles (SSTS 15 de febrero y 18 de diciembre de 2006; 19 de octubre 2007); todo lo cual conduce a criterios de limitación de la imputabilidad objetiva para recordar que no puede cuestionarse esta toma de decisiones si el reproche se realiza exclusivamente fundándose en la evolución posterior y, por ende, infringiendo la prohibición de regreso que imponen los topoi (leyes) del razonamiento práctico (SSTS de 14 de febrero de 2006, 15 de febrero de 2006, 7 de mayo de 2007)".

En otro punto, continúa la Sentencia argumentando lo siguiente:

“...en ningún caso los hechos probados de la sentencia han puesto en evidencia la existencia de una actuación negligente de los demandados ni en el diagnóstico, ni en la intervención que llevaron a cabo ni, en fin, en el origen de un daño cierto y real causado por estos al menor, entre otras razones, porque la lesión de plexo braquial no viene producida por una acción u omisión integrada en el ámbito de la actuación de los ginecólogos, y porque tampoco la cardiopatía resulta de ningún acto médico, por ser de carácter congénito, ignorando si una nueva ecografía o ecocardiografía fetal en un embarazo normalizado hubiera proporcionado una solución distinta, puesto que la culpabilidad de los facultativos bajo cuyo control se puso el menor una vez nacido se fundamenta de una forma simplemente especulativa a partir de un daño que no se concreta, ni aparece relacionado con el supuesto retraso diagnóstico que se imputa al servicio de neonatología que prestaba asistencia en las dependencias de la Clínica. El daño fundamenta la responsabilidad y éste no aparece asociado a una 
actuación u omisión negligente o culposa, que toma como medida de diligencia lo que se conoce como "lex artis ad hoc", o criterio valorativo para calibrar la diligencia exigible en todo acto o tratamiento médico, puesto que se ignora que es lo que debieron hacer que pudiera haber evitado "el perjuicio sufrido por la tardanza o retraso en el diagnóstico de la cardiopatía que sufría con carácter congénito", como se ignora si, de haberse producido el daño, no estaba directamente relacionado con la enfermedad y sí con alguna actuación médica de los ginecólogos o de los neonatólogos que pudiera haber influido o agravado su desarrollo".

\section{El fallo de la sentencia del Tribunal Supremo}

Es del tenor literal siguiente:

“Fallamos Declarar lo siguiente:

10) No haber lugar al recurso extraordinario por infracción procesal formulado contra la sentencia dictada por la Sección 19 de la Audiencia Provincial de Madrid, de fecha 15 de julio de 2005, por el Instituto de Religiosas San José de Gerona, entidad propietaria de la Clínica Santa Elena, y estimar los recursos de casación formulados por las representaciones legales de D. Ambrosio, Doña. Constanza, Clínica Santa Elena y Mapfre Caja Salud De Seguros y Reaseguros, S.A.

$2^{\circ}$ ) Casar la Sentencia recurrida, dejándola sin efecto.

$\left.3^{\circ}\right)$ Dictar otra por la que se desestima la demanda interpuesta por Don Luis Pablo y Silvia frente a D. Ambrosio, Doña Constanza, Clínica Santa Elena y Mapfre Caja Salud De Seguros y Reaseguros, S.A, a quienes se absuelve de la misma.

$\left.4^{\circ}\right)$ Se imponen a la parte actora las costas de la $1^{a}$ Instancia y no se hace especial declaración de las causadas en apelación y en este recurso, salvo las originadas por el recurso extraordinario por infracción procesal, que se imponen a la Clínica Santa Elena."

\section{Conclusión}

Así las cosas, a nuestro entender podemos sacar las siguientes conclusiones:

- El médico, en su ejercicio profesional, es libre para escoger la solución más beneficiosa para el bienestar del paciente.

- La obligación del médico o profesional sanitario siempre es de medios, no de resultado.

- La diligencia del buen médico comporta no sólo la elección adecuada, sino el cumplimiento formal y protocolar de las técnicas previstas para cada caso.

- La "Lex artis ad hoc" es un concepto jurídico indeterminado que debe establecerse en cada caso. Lo que más se le parece suele ser un protocolo de actuación médica, aunque el protocolo nunca puede agotar el contenido de la "lex artis", que le supera siempre visto que la "lex" se nutre de toda buena práctica médica y no sólo de la establecida por el protocolo.

Por eso, y pese a que en el pleito se discutió ampliamente si la decisión de que el parto fuera vaginal en vez de por cesárea fue la correcta, al no existir ninguna indicación en el momento que demostrara que era preferible la cesárea, la decisión fue la correcta. Otra cosa es que los hechos complicaran esa decisión -como desgraciadamente ocurrió- pero dichas complicaciones, según la Sentencia, no pudieron ser previstas antes de que ocurrieran. En suma, el Tribunal califica la actuación de los médicos conforme a la buena práctica médica, y por ello los absuelve de las consecuencias dañosas que lógicamente no pueden imputárseles.

Y es que, como ya dijera Hipócrates hace muchísimo tiempo, la profesión de médico no sólo está claro que es enteramente un arte, sino que vistas las decisiones a las que hay que enfrentarse en la práctica, es una profesión vocacional y de riesgo. Por eso, y aunque a veces nos pueda molestar cierta sana envidia acerca de la también dedicación de Galeno, un servidor prefiere matar el gusanillo viendo los martes al Doctor House. Mi serie favorita, claro... 